\title{
Political scientists on the functions of personal pronouns in their writing: An interview-based study of 'I' and 'we"*
}

NIGEL HARWOOD

\section{Abstract}

In contrast to the numerous corpus-based studies of pronouns in academic writing, this paper uses qualitative interviews in an attempt to account for academic writers' motivations for using the pronouns ' $I$ ' and 'we' and to describe the textual effects that each case of ' $I$ ' and 'we' helps to create. Five political scientists took part in the research, commenting upon their pronoun use in one of their own journal articles and also in the other informants' texts. Seven textual effects that ' $I$ ' and 'we' help to construct are identified and described. ' $I$ ' and 'we' are said to help (i) make the readership feel included and involved in the writers' argument; (ii) make the text more accessible; (iii) convey a tentative tone and hedge writers' claims; (iv) explicate the writers' logic or method regarding their arguments or procedures; (v) signal writers' intentions and arguments; (vi) indicate the contribution and newsworthiness of the research; and (vii) allow the writer to inject a personal tenor into the text. The insights and implications of the study are discussed and the paper closes by proposing that similar interview-based studies could be used for pedagogical purposes in English for academic purposes (EAP) contexts.

Keywords: Academic writing; personal pronouns; political science; discourse analysis; interview-based research; persuasion.

\section{Introduction}

Of the numerous corpus-based studies of pronouns in academic writing, Ken Hyland's work in particular is impressive in that it features corpora of a considerable size to provide us with an understanding of how pronouns are used across a range of disciplines at both a quantitative and a qualitative level. Hyland (2001b), for instance, features a corpus of 
240 research articles (RAs) in eight disciplines running to 1.4 million words. And although Hyland (2001a, 2001b, 2002) supplemented his investigations with some interviews, the main focus of these studies is on the corpora rather than on the interviewees. The present paper takes a rather different approach and uses a far more modest data set. It is limited to a single discipline, political science, and rather than relying on corpus analysis, it relies on interviews with the writers of five RAs. These writers were asked to explain the motivations behind their own first-person pronoun use and to describe the textual effects each case of 'I' and/or 'we' helps create. They saw the other informants' texts and commented on 'I' and/or 'we' in these also. So while this study can make no claims to provide generalizations about disciplinary pronoun use in the way that corpus-based studies like Hyland's do, it can provide us with an insight into the intended pragmatic effects of 'I' and 'we' in a small number of individual writers' texts in a single discipline. In contrast to the corpus studies, then, I allow writers to speak about their own work and that of their colleagues rather than attempting to speculate on the motivations that underlie the writers' pronoun use myself. While I will argue later that interview-based studies cannot replace corpus-based studies, it will be claimed that they complement them, and that the two approaches should be used in tandem. The present study resulted in (i) a taxonomy of pronoun functional-pragmatic effects, which is then compared with the functional taxonomies of corpusbased pronoun investigations; and (ii) an account of the writers' motivations for wishing to bring about these effects-motivations that would necessarily remain occluded to corpus-based investigators. It will be argued that while the corpus-based taxonomies that discourse analysts have postulated are not dissimilar to the taxonomy explicated here, the present interview-based approach allows us to appreciate the writers' preoccupation with making their prose maximally persuasive. The study also affirms that pronouns can be polypragmatic, as writers sometimes report a desire to accomplish two or more effects simultaneously with one pronoun. I begin by saying a few words about pronouns in general and about the insights corpus-based studies have provided us with. I then offer my own analysis, organizing this around seven functions the informants attributed to their own and their colleagues' pronoun use and illustrating these with extracts from the interviews and from the informants' texts. I end with a discussion of the insights of the study and some thoughts on the strengths and weaknesses of the interview-based approach in general and for applied linguists who are working in the field of English for academic purposes (EAP) who wish to enhance EAP pedagogy. 


\section{Personal pronouns in academic writing}

There have been a number of corpus-based studies of academic writing that have focused on the effects personal pronouns help to create (e.g., Bernhardt 1985; Chang and Swales 1999; Harwood 2005a, 2005b, 2005c; Hyland 2001a, 2001b; Kuo 1999; Tang and John 1999; Vassileva 1998). Pronouns are said to help the writer organize the text and guide the reader through the argument (e.g., First I will discuss $x$ and then $y$ ); define terms (In this article I use the term ' $x$ ' to mean y); state personal opinions, arguments, and knowledge claims (On the basis of my data I would claim ...); recount experimental procedure and methodology (We interviewed 60 subjects over the space of several months); and acknowledge funding bodies, institutions, and individuals that contributed to the research in some way (I thank Professor X for his help with the calculations). In addition, pronouns can help to reveal how academic writers construct their relationship with readers and with their discourse community (Kuo 1999). So while some uses of 'I' and 'we' are said to be low-risk instances of textual intervention on the part of the writer, other uses, such as when the writer makes a claim, carry much greater threat to face and are potentially points at which the writer is vulnerable to attack by the audience. Hence researchers who have constructed functional personal pronoun taxonomies (Harwood 2003; Hyland 2002; Ivanič 1998; Tang and John 1999) link pronouns with authorial presence.

The 'we' pronoun can operate inclusively or exclusively. That is, while inclusive 'we' is used to refer to the writer and reader together, exclusive 'we' refers solely to the writer and other persons associated with the writer. Unlike some other languages, English does not differentiate formally between inclusive and exclusive 'we' (see Quirk et al. 1985; Wales 1996). Although this lack of semantic distinction can be frustrating for the discourse analyst, researchers claim it can be exploited by writers. Wales (1996: 58) says it makes for 'a useful ambivalence politically speaking', while Pennycook (1994) argues that the selection and use of pronouns can reflect power relations. Inclusive 'we' is said to help academic writers personalize the text, constructing a 'chummy', 'intimate' tone (Wales 1996). Audience involvement results from the feeling that the argument of the text emerges from a collaborative writer-reader effort (Wales 1980). This attempt to involve the audience can therefore be seen as a manifestation of positive politeness. But this involvement also serves rhetorical ends. The ultimate aim of the academic writer is to ensure that their claims are ratified by readers (Gilbert 1977; Latour 1987); hence one of the writer's motivations for making the audience feel involved is to enhance the persuasiveness of the text. The writer will be trying to get 
readers to see things their way, and thus accept the arguments advanced. Finally, both inclusive and exclusive pronouns can serve as negative politeness devices (see, for instance, Myers 1989). As Markkanen and Schröder (1992) suggest, 'I' can constitute a hedge (on hedges, see also Dubois 1987; Prince et al. 1982; Salager-Meyer 1994, 1997; Hyland 1998a, 1998b). 'I' can show that while the writer is persuaded of a certain point of view (e.g., I think ..., I feel ...), they leave it to the readers to determine whether or not the claim is justified (for more on inclusive and exclusive pronouns, see Harwood 2005c). ${ }^{1}$

\section{Pronouns and cotext}

It should be noted here that cotext — defined by Janney (2002: 458) as 'the immediate linguistic environment in which a unit of discourse ... occurs ... in a discourse sequence'-also plays a part in the effect that pronouns help to create, something I have remarked upon elsewhere (Harwood 2005a, 2005b, 2005c). An instance of how cotext can work in concert with pronouns can be seen in the extract 'First, we consider audience costs ...' from one of the informant's texts. While corpus-based taxonomies would identify the pronoun here as organizing the discourse, obviously the adverbial 'First' plays a part in organizing the text, too. Hence, it is more accurate to talk about ' $\mathrm{I}$ ' and 'we' helping to create a textual effect with the cotext rather than giving the impression that the effect is achieved solely through the use of the pronoun. ${ }^{2}$

With this in mind, then, the aim of the present study was not only to get an insight into the informants' motivations and intentions underlying their pronoun use, but also to begin to compare and contrast these accounts with the pronoun functional taxonomies put together as a result of corpus-based investigations. While this study in no way purports to have a large enough data set to do this systematically, consisting as it does of only a handful of informants in a single discipline, it does at least provide an initial point of comparison.

\section{Methodology and procedure}

Potential informants from a department of political science at a British university were chosen at random and contacted via email to ask whether they would be willing to participate in the study. Those who responded positively were then asked to send me a paper or electronic copy of a 
recent article they had published. The study was limited to five informants who are identified as POL1-POL5 in the data analysis below. It turned out that the informants were from a number of different political science traditions. While all informants engaged in empirical work, POL4 also wrote political theory/philosophy. And while all informants used quantitative analysis to some degree, POL2 built and tested quantitative models and hence his paper contained far more statistical data than the other texts. I have not provided any further details about the informants in the interests of maintaining anonymity, although research related to the informants' beliefs about writing in the discipline of political science in general and about appropriate and inappropriate pronoun use in particular can be found in Harwood (2006).

I examined all occurrences of ' $I$ ' and 'we' that featured in the informants' texts and highlighted each of them before showing the highlighted texts to the informants and asking them to comment on both their own and their colleagues' pronouns. The interview format was of the semi-structured type (e.g., Cohen et al. 2000), and was sufficiently flexible to allow the interviewer and interviewee to develop the conversation, so that both parties were 'active' (Holstein and Gubrium 1995, 2003; Kvale 1996; Mason 2002). ${ }^{3}$ During the interview, informants were asked why they (and their colleagues) used 'I' or 'we' where they did and the effect each case of 'I' or 'we' has. The interview was piloted and modified.

During the analysis I read through the interview transcripts, summarizing the informants' views and including quotes from the informants in these summaries as part of an attempt to broadly describe prominent themes. These summaries and themes were then grouped and described more precisely under headings. The data were then re-examined in their entirety and coded according to these themes. During coding, the themes were revised and refined to truly reflect the data, and the categories were renamed to reflect the nature of the informants' comments more precisely. Although the coding process was only done once, this was not seen as definitive. This initial coding was simply a launch pad for a much more detailed analysis that attempted to capture the essence of the data in each category (cf. Mason 2002; Wolcott 2001), which was then examined for connections and disjunctures. This more detailed pass at the data was effected by writing. I summarized what the informants said about each of the pronoun functions I had provisionally identified, including representative quotes in an effort to portray these views as faithfully as possible. What follows is an extract from my account of POL1's interview, which was categorized under the function of including the reader (see 5.1 for a detailed analysis of this category): 
Commenting upon an inclusive 'we' which features in his text, POL1 differentiates it from an exclusive use ("that was me and the readers, rather than "we" as in Queen Victoria'), and states that its function is to 'invite the reader to join in the sort of experiment'. Similarly, POL1 explains POL4's use of inclusive 'we' as part of a text where POL4 is 'sometimes having a conversation with his readers, or he's inviting them to join him in his opinions'.

Once I had recorded each of the informants' views in this way, I then compared and contrasted what each informant had to say on a pronoun function, and wove each of the informants' accounts of this particular function into a single account. At times, contrasts and disjunctures occurred where interviewees commented on their colleagues' pronouns, identifying the pragmatic effects that these writers were accomplishing with the pronouns, but making clear that their colleagues' practices were not to their own taste, and are discussed in detail in Harwood (2006). Finally, I went through the analysis once more, reorganizing and clarifying my written accounts where necessary by referring directly to the interview data. As Wolcott (2001) argues, during this writing, re-writing, and revisiting of the data, further re-analysis was taking place. In other words, the process of analysis was recursive (cf. Miles and Huberman 1994).

\section{Data analysis}

All of the writers used 'I' and/or 'we' in their texts. The frequencies are not included here as the focus is on function not frequency, but can be found in Harwood (2006). On the basis of the informants' accounts, seven textual effects were identified that 'I' and 'we' help to construct. Each of these is discussed below.

\subsection{Including the reader}

The extracts discussed in this section reveal how academic writers attempt to make the readership feel included and involved in the construction of the argument in order to heighten the rhetorical effect of their claims and get the reader onside so that they support the writer's position. ${ }^{4}$ Accordingly, when looking at specific cases of 'we' usage in her text, POL5 is clear that she is using 'we' in an inclusive rather than an exclusive sense, 'inviting' the readership to form a 'partnership' with her:

(1) POL5: so the we is not just a royal we but it's a partnership we ..., I am inviting people to look at Table 3 with me and see very clearly that the impact was not what everybody expected ${ }^{5}$ 
In the same way, POL5 calls another case of inclusive 'we' that she uses to refer readers to a table "participative "we"':

(2) POL5: [reading text] 'We can also assess the impact'. Well that's really the same thing, it's a participative we. If you look at table 4, you can see just as I can

I: $\quad$ So you're asking the readership

POL5: Yes! To journey with me ..., I've said, 'Ah! This is interesting!' I'm showing you to look at it and to conclude the same as I, basically! [laughs]

What is also interesting is that the willingness of POL5 to inject participation and inclusion into her text is determined by her estimation of the persuasiveness of her arguments. If she feels less than confident that the readership will go along with her version of events, she says she removes the inclusive pronouns from her text:

(3) POL5: somebody might look and say 'Hey! You know, I think this is much more significant than the author is claiming'.

I: $\quad \ldots$ but presumably when you use we to include everybody, you're fairly confident that they won't do that?

POL5: Yes I am.... I'm quite confident ... And if I hadn't been, then I would have been much more tentative and I would have said something like 'This information is open to two different interpretations' or 'several different interpretations', so I wouldn't have had a we.

As POL5 puts it later on in the interview, when she feels she can safely assume 'my reader sees the same thing as I do' from a table, inclusivity can be safely introduced without threat to the writer's face. ${ }^{6}$ In the same vein, POL2 talks about including the audience when he refers to a finding he feels confident the readership would not take issue with, given that he can safely assume the audience is in possession of the necessary level of disciplinary knowledge and competence: ${ }^{7}$

(4) POL2: it actually really refers to a very standard finding and so by saying 'we observe' we've more or less said like, ok, 'as all of you probably', you know, 'whoever goes to the trouble of reading this article would already have concluded for themselves that there is not a pure strategy equilibrium, we observed the same thing'

The way that pronouns help writers inject inclusivity is also apparent from POL4's interview. He reports that pronouns can help him 'get a sort of conspiracy going with the reader'. The idea is that POL4's inclusive pronouns should help make the audience feel involved and 
work through the logic of the text in the way the writer wishes them to so they are persuaded of the validity of POL4's arguments and are willing to ratify his views. Commenting on POL4's text, POL5 captures this inclusive element by saying that POL4 is 'trying to encompass his readers', 'taking them with him'. When I asked POL4 to say more about what this 'conspiracy' consists of and how it works, he agreed he was trying to 'carry the reader along'. POL4's 'conspiracy' will be discussed more fully in 5.2, since it can also be seen to enhance the reader-friendliness of the text.

Whereas the authors of all the extracts discussed to this point have displayed an awareness of how including and involving the reader can help make their arguments persuasive, it is interesting that persuasiveness can also be introduced unconsciously, as the following extract from POL3 demonstrates. POL 3 reads an extract from his text and wonders why he in fact used an inclusive pronoun rather than the more impersonal 'researchers':

(5) POL3: [reading text] 'If we are prepared to make assumptions'. 'Unless we are prepared to make some assumptions about causal ordering, we cannot proceed....' ... I could have said 'researchers' there. Quite why I used we, I think I'm trying to make them [i.e., the readership] more complicit with me, I'm trying to convince them that this is actually what they have to do in order to do any analysis, so there's a kind of, almost a rhetorical use there, isn't there, which I'd not thought about, I didn't do deliberately

\subsection{Helping the reader}

Some of my informants' texts, POL2's in particular, featured lengthy quantitative analysis and model-building, which looked to me as a nonspecialist to be more economics than politics. And it was apparent that POL2 is very conscious that not all of his audience will be as well versed in statistical analysis as they should perhaps be. Although he says that the mathematical parts of the article are 'awful parts to write', pronouns help make things easier for the reader. The helping theme that emerged from his interview therefore relates to how pronouns enhance the readerfriendliness of the text:

(6) POL2: this [is] the most awful stuff to write, because it uses also a lot of mathematics that you start introducing. And by using we you can also make it a little bit less daunting for the reader to have to go through it. So it's almost putting the 
reader somewhat at ease ... So I think that's my objective there. ${ }^{8}$

POL2 goes on to contrast the way economists would do things with the way political scientists do things. His point is that, in his view, economists can safely take it for granted that their audience is possessed of the necessary expertise, which means that less thought would be needed to helping readers through the text:

(7) POL2: For me, when I write this, when you write a formal model, I think there are basically two approaches to it. The one is, I think ... normally assumed by the economist, which is not to care about it at all, simply get it over as quickly as possible

I: $\quad$ Without the we?

POL2: Without the we, and also without little words in between the mathematic symbols.... Now if you go that way, if you go [with] very little text, your audience have to be very highly technical qualified, and this particular journal,... well you could try to do it but it would not really sit well with the level of the analysis. So in this case, given the kind of analysis it is, it's better to kind of keep it a little bit easier.

POL2 wishes to have a less specialized audience read his article, and in order to make this possible, he ensures the text features reader-friendly pronouns, which would have been extraneous had he been addressing an audience of economists well versed in the kind of economic modeling he is engaged in:

(8) POL2: Well, if I would lose all of this, let's say lose all the words and all the [inaudible] things, you would basically tell the readers this is only for people who are extremely technical.... but if you want to make a contribution also conceptually or more broadly speaking, then you also have to collect a different readership, a readership that would be very unhappy if you completely make it mathematical. So you have to come up with a reasonable way to present this, the text.... so the idea of occasionally having a personal voice in there, makes it I think more attractive to the reader

So POL2 uses pronouns at specific points in his argument where he anticipates the audience will have difficulties, agreeing with my statement that 'sometimes if the calculations are quite dense and difficult, you use "we" to lighten it up'. 
While POL4's political philosophy text is very different from the quantitative statistics and model-building in POL2's text, POL4 also reports using pronouns to help the reader through the argument and to make the text more accessible. And here we return to what POL4 calls the 'conspiratorial' element to his text that we began to explore in the previous section. In a fascinating commentary on his phrase 'I find it helpful to present the relevant information ... in the form of a table', POL4 says he is 'helping the reader think through the logic', and is 'giving the reader directions'. POL4's attempt to make things as easy as possible and provide the reader with 'a helpful tip' will hopefully bring the reader onside so that he/she will sympathize with the writer's argument; and by constructing solidarity with the audience, this will 'get a sort of conspiracy going', so the readers will see things in the same way as POL4:

(9) POL4: now [reading text] 'I find it helpful to present the relevant information' ... this is ... a bit like giving someone directions, 'Well you could go this way or you could go this way, but I find it helpful to go that way, because actually you can buy a bag of chips on the way', or something like that. [reading text] 'We can think about the game as a minipolitical system', that is myself and the reader, thinking through the logic of this and that then goes for all of these subsequent wes, so [reading text] 'we can', so you and I, readers and us together, we set it up in this way, according to your helpful tip ..., so that's just ... trying to get a sort of conspiracy with the reader going, I think.

POL4 agrees with my summary that he is 'presenting the argument in a more digestible form because he's aware it's quite heavy', and goes on to say more about this. POL4 is in fact commenting upon another scholar's work and claims that this researcher's way of presenting things is 'rather confusing'. Hence POL4's table and his 'helpful suggestion' to the reader to see things in the form in which he chooses to present the argument. Again it is the writer who remains in charge throughout, despite the trappings of inclusion and 'conspiracy': indeed, POL4 thinks of this rhetorical technique of presenting the reader with a readily accessible example as a pedagogical device of the sort he may use in his lecturing. Thus there is a sense that the (apparently expert) audience is being constructed as neophytes.

(10) POL4: so one of the things I'm trying to do here is to give a concrete example, and there I suppose there's a conspiratorial element with the reader, think about this example which is 
easy to grasp, it's intuitively pretty straightforward, I use that a lot in my teaching.

POL4 also makes clear that while he 'hopes the reader's followed through the logic of the argument', he nevertheless ensures he provides explicit statements of where the reader should have got to. He glosses the extract 'We are ... back to the problem ...' in his text as 'if you were to think about the logic of this position, this is where you'd be'. Hence POL4 leaves very little to chance, providing the reader with the opportunity to follow through the logic of his argument, but also explicitly stating the conclusion the reader should reach as well. While pronouns like these operate on one level to enhance the accessibility of the text, on another level they can be seen as helping the writer persuade the audience of the validity of their arguments.

\subsection{Hedging an argument: Tentativeness, judgment, authorial responsibility}

There were a number of extracts where the informants spoke of how pronouns helped to convey a tentative tone in the face of anticipated disagreement (or at least the possibility of disagreement) from the readership. This category therefore brings to mind research that suggests that pronouns help writers to hedge their claims (e.g., Hyland 1996, 1997, 1998a, 1998b; Markkanen and Schröder 1992; Myers 1989). ${ }^{9}$

The first extract to be discussed here is from POL3, who actually uses the term 'hedging' unbidden, in the phrase 'hedging my bets'. POL3's text is forecasting the result of an upcoming major political election, and I asked him to comment on the extract 'It is in the spirit of considerable uncertainty - and, I hope, humility - that the forecasts above are reported':

(11) POL3: I suppose I'm hedging my bets as much as possible, and I'm perhaps laying it on too thickly. But the thing is that there are some people who do forecasts with quite a lot of arrogance and I know that a lot of people think that I'm mad doing forecasts cos it's risky, and I really did want to convey that I was even less certain about these forecasts than I had been about [previous] forecasts....

While POL3 is aware that he could be seen as overdoing things, and could therefore be accused of an insincere, stylized humility, as he points out, election forecasting is a hazardous enterprise. His comments on the extract, 'I am bound to say that I do not find this a very convincing forecast', make explicit just how imprecise this type of work is: 
(12) POL3: while I can do forecasts, I actually don't think it's a very useful exercise.... I could have produced any forecasts for any kind of outcome, and the problem is that you can't differentiate among the competing models, you can't tell which of the models is best, and you can make [a] judgement, but you can't have a statistical ... set of criteria that would tell you which of the models is best. So I really wanted to indicate that was my view and that's why I used I there.

Hedging is therefore not a stylistic device to be exploited by the cowardly who are too scared to make an emphatic claim, but rather a device to help the writer tell the truth about the extent to which any election forecast is necessarily speculative (cf. Banks 1994; Hyland 1998a, 1998b; SalagerMeyer 1994, 1997).

POL1 is also fascinating on hedging as a rhetorical device. He comments on an extract from POL4's text that reads 'Looking at the rows in Table 1, we could then say ...', and speculates that the use of the inclusive 'we' could serve to deflect responsibility away from the writer in the event of the claim being falsified. However, POL1 seems to discount the possibility that POL4 could be hedging, due to POL4's (esteemed) status ('he's a star'), which apparently enables him to 'get away with' making contentious claims that less eminent figures would be unable to make:

POL1: ... a thought occurred to me ... just wondered whether people could say [reading text] 'Looking at the rows in Table 1, we can say' if they were trying to-how should I put it? - not be too singularly associated with the idea in case it's wrong or using we in a speculative way. That's not how [POL4] would use it, he's a star, but it seems to

I: $\quad$ To distance themselves from taking responsibility?

POL1: A little bit, if I read that kind of sentence in a $\mathrm{PhD}$ thesis that's how I might have interpreted it, but not from [POL4], no, he can get away with it, others can't

I: Is that because he's held in such high esteem?

POL1: Well ..., he's very bright, so he clearly hasn't used it in that sense

When POL1 comments on POL4's use of 'I think' later on, however, he concludes that POL4 does hedge after all, which highlights the sense 'that perhaps this claim is not completely certain or verifiable'.

(14) POL1: [reading text] 'This conceptual alignment is, I think, the reason why' ... So ... he could have said 'This conceptual 
alignment is the reason why', and that's a very strong claim, by saying 'This conceptual alignment is, I think ...', he's conceding to the reader in a sense that perhaps this claim is not completely certain or verifiable but he's giving an opinion, so that is quite legitimate.

As POL1 says, one way in which POL4 uses pronouns is to signal 'this is my opinion, as opposed to hard fact'. And when POL4 talks about his own text, he confirms that he uses the phrase 'I think' to hedge, flagging up the fact that he is less than certain about the truth of his argument. Commenting on the extract 'We are, I think, back to the problem ...', he says that "the "I think" there is intended to say, "well look I don't think this is watertight ..."'. POL4 adds that pronouns are used to express 'conjecture' and 'judgement', 'suggestion rather than strict deduction'.

POL4 also uses the 'I' pronoun to give his audience the rhetorical space to differ in their interpretation. POL5 understands immediately that POL4's 'I find it helpful to present the relevant information ... in the form of a table' acts as a hedge in case the audience does not in fact find POL4's table as clear as he anticipates that they will:

(15) POL5: [POL4's] telling us that he found it helpful, and I presume the implication is that we will also find it helpful, but he's maybe not as confident as I was in saying 'You will find my table [laughs] to reveal x'. He's saying, 'Well I found this helpful, you may too'. ${ }^{10}$

The final extract discussed here again involves a hedge used by the writer to save the audience's face and to give them the option of interpreting things differently. However, it is particularly interesting because it also raises the question of the extent to which academic writers consciously set about making a text rhetorically effective by means of hedging. How much is conscious strategy and how much is unconscious force of habit ('I was just in "we" mode really')? Discussing the implications of her study, POL5 writes 'We can identify three related areas where the implications ... would be felt most keenly', and freely admits she finds the fact that she used a pronoun here as being 'puzzling to me, because it could have been worded without any "we", , as in 'There are three related areas':

(16) POL5: I suppose this is tentative, because other people might see, 'Oh I can identify another one'. I'm really saying 'In my view, these are the important arenas where [inaudible] there were implications of the elections'.... But I could have said, 'The implications were, would be felt most keenly in three areas', or I could have had a different 
subject, so that is more surprising. I suppose I was just in we mode really [laughs], but also offering tentatively that this is my judgement about it, it would be harder to say 'There were three', because that would be a matter of judgement

\subsection{Elaborating the logic/method of an argument or procedure}

Commenting on the extract from his text, 'I accordingly do not de-trend the various independent variable measures', POL3 reports 'I' is being used 'because it's what I did'. Hence pronouns can help writers explicate their method and procedure (see Harwood 2005a for a more extensive discussion of the role pronouns play in elaborating method). While what Harwood (2005a) calls 'method pronouns' can seem at first glance unremarkable, merely helping writers to itemize their workings and/or logic in what POL4 calls 'cookbook' fashion in a comment on POL2's text ('they're giving the cookbook about how they actually did it'), as POL5 makes clear, method pronouns can help writers underscore the distinctiveness of their analysis and make themselves accountable for their claims. While they flag up the writer's procedure as their own, it is up to the audience to decide whether the writer's way of doing things is legitimate. Hence, inclusive pronouns would be inappropriate. Commenting on the use of POL3's 'I accordingly do not de-trend the various independent variable measures', POL5 says:

(17) POL5: Now he's back to I, because ... he's got to explain things that he did, he has to show people, [reading text] 'I don't de-trend'....... But here he is showing what he distinctively has done, so that people can judge it. And he's offering himself for judgement in both of these. So if I were doing that I would have to have an I, I think. I'm taking the blame, I, not hiding in some we. ${ }^{11}$

Similarly, POL5 describes how many of the pronouns in POL2's text serve 'to specify a whole set of assumptions, conditions, parameters, and strategic decisions' about the way in which the model-building and the analysis that follows was done. As POL5 neatly puts it, these types of method pronouns can be seen as signifying 'This is what I've had to do to end up here'.

\subsection{Signaling intentions and arguments}

This category is similar to the 'Discourse Guide' function identified in the work on pronouns elsewhere (e.g., Tang and John 1999), which orient the 
reader. Hyland's (2002) 'Stating A Purpose' category, for instance, describes pronouns that help writers 'to state their discoursal purposes in order to signal their intentions and provide an overt structure for their texts'. Hence, POL1 says he employs pronouns 'to tell the reader what I'm going to be doing later on', and 'to set out my stall'. He reports using pronouns in this way 'very much at the beginning of the paper or at the beginning of sections'. Accordingly, his introduction features language like 'In this article, I explore ...', 'I begin by ...', 'I then examine ...', and 'Finally, I draw some conclusions ....' Of course these signaling devices can also be seen as enhancing the reader-friendliness of the text in the same way as the examples discussed in 5.2, which help the reader follow the thread of the argument. As POL2 explains, phrases in his article like 'First, we consider', 'structure the text for yourself [i.e., for the author] as well as the reader', and 'take the reader by the hand'. Similarly, POL4 talks of pronouns as 'scene-setting' or 'stage-setting'; they are used

(18) POL4: to give the reader a sense about what sort of structure the argument's going to be, so it's a bit of scene-setting really_-saying what I am going to do.

POL4 identifies 'stage-setting' as occurring throughout POL2's text, where POL2 and his coauthor are outlining their procedures. POL4 explains how the pronouns serve the needs of the readers by breaking up the text and making it more readily digestible:

POL4: [reading text] 'we consider', 'we have included', 'we only find', 'we control for', 'we turn again to', this is all stagesetting stuff, here's what we're doing in the argument, here's where we are, pause for breath, let us tell you what we're doing. ${ }^{12}$

Commenting on POL1's pronoun use, POL4 again uses the 'pause for breath' metaphor, saying the pronouns can help the researcher orient the reader by indicating that 'I'll take you around and guide you'.

POL3 only identifies one pronoun in his text as performing a signaling function, but it provides a fascinating example of how academic writers consider their readership when composing. POL3 writes 'One final set of estimations is necessary before we consider the forecasts ....' Thus POL3 signals to the audience that his forecasts will be delayed despite anticipating the readers' desire for him to move on to his findings. However, POL3 feels the delay is necessary despite the fact that it may be unwelcome:

(20) POL3: What people want to get to are the forecasts, they want to understand how I've got to the forecasts, which is what all the previous stuff is about, but what they really want is, 
what's going to happen? What do you think's going to happen? Cos we want to see if you're wrong. And here I'm having to say 'Look, sorry, but there's yet another reason why I can't go to the forecast yet ...'. And so that's what's being provided there.

POL5 says something rather similar when commenting on POL1's text, revealing the importance of writers' anticipating the audience's needs and expectations throughout. Signaling pronouns can guard against 'impatience' on the part of the readership; by acknowledging the concerns of the audience as the writer sees them, the writer can organize things in the way they wish without losing the readers' goodwill:

(21) POL5: But he's back to I-[reading text] 'I return to the issue of transaction costs', but that is ... 'I'm going to do it but I'm going to do it later, so don't get impatient with me that I haven't done it yet'. 'I do know it has to be done'.... But here again [reading text], 'As I argue later' ... there's another instance of 'Yes I know you want to know about selection rules, but that's coming'.

The final signaling extract considered here underscores the fact that these signaling devices can serve to enhance the persuasiveness of the text. Commenting on POL1's use of the phrase 'Moreover, as I argue later', POL4 makes it clear that in his eyes such phrases do not simply provide helpful guidance through the intricacies of an argument, but actively seek to persuade the readership of the wisdom of the writer's views:

(22) POL4: Now, [reading text] 'Moreover, as I argue later' is very interesting, and I've used this formation myself. And the way I would read this ..., is it's not just saying 'This is what I'm going to say ..., it's actually if you like reinforcing that this is the argument and this is part of the argument that I'm trying to persuade you of....

I: $\quad$ So it's underscoring the importance of the argument or the centrality of the argument, is it?

POL4: Yeah I think so. But it's also got a slight sort of 'I'm going to really sort of nudge you a bit this way', it's ... 'You'd better be persuaded because of all this work I've done!' [laughs]

Hence there is a sense in which the reader is being told in advance that this particular argument is central; the writer is getting their persuasion in sooner rather than later. 


\subsection{Indicating the contribution and newsworthiness of the research}

A number of studies (e.g., Berkenkotter and Huckin 1995; Gilbert and Mulkay 1984; Haggan 2004; Harwood 2005b; Kaufer and Geisler 1989; Knorr-Cetina 1981; Latour and Woolgar 1979; Law and Williams 1982; Whitley 2000) have shown how researchers are intent on flagging up their research as newsworthy and worthy of their peers' attention. Accordingly, informants spoke of how pronouns helped emphasize the scholarly contribution, originality, and/or newsworthiness of their work. For instance, POL2 explains how foregrounding novelty is 'good practice' in the RA genre:

(23) POL2: It is considered to be good practice to tell quite early on what the particular contribution of the article is, and so the use of we is very much an exercise, now we're not reviewing what other people are doing, we're not talking in general about why this is a relevant topic but we're emphasizing this is our contribution, this is what we have done in this particular article, it's what we find ${ }^{13}$

Although ostensibly serving to signal the contribution to the pursuit of knowledge, these exclusive pronouns are also rhetorical, directly signaling to the readership that they should take note and 'pay attention' because of the uniqueness of the research:

(24) POL2: That is somewhat of a contribution of the data and myself ..., it's not a very standard way of dealing with the particular issue. And it also allows us to pull these three models together.... And so there's also the notion of trying to emphasize that this is what we do here, and pay attention

Similarly, POL2 reports that the exclusive 'we' form can help the reader 'pick up' that the author's contribution is 'slightly different' from what is in the rest of the literature.

While POL5 confesses that she's 'something of a minimalist' when it comes to using pronouns, and uses far fewer than POL2, she reflects that one of the factors that seems to determine how heavily pronouns are used in the text relates to the originality of her contribution:

(25) POL5: Then this is the bit of the paper where there is my original work that I had to sit down and do these calculations.... So I think to some extent it depends what proportion of the paper arises because of something that I have done. I'm doing something at the moment but it's with a coauthor.... And there are more wes in that piece simply 
because ... we've set out to answer a question, and then we went and looked at the data and did things with the data. So it depends to some extent on how much, I mean of course it's all original in the sense that it's a distinctive synthesis, but it depends on doing a specific kind of analysis, if that's weightier then there would be more pronouns.

Similarly, POL5 makes clear that pronouns can help a writer show what his/her particular 'take' or 'standpoint' is. Commenting on POL4's text, POL5 claims that it is particularly important for political theorists/ philosophers to mark out their unique way of 'unravelling things':

(26) POL5: [reading text] 'It is this claim about the logic of political choice that I wish to concentrate on', well this is [POL4's] argument, and it is his logical dissection. And I would have probably too chosen $\mathrm{I}$ in this circumstance as well $\ldots$, and I think political theory is probably quite a good exemplar of where you've got to try and show your Iness, 'I've unravelled this in this particular way, so I shall argue' ...

\subsection{Injecting a personal tenor into the text}

Two of the informants also spoke about how personal pronouns help them inject what POL5 describes as a 'personal note' into their arguments. POL4's text was written in memory of a former colleague. Not surprisingly, then, POL4 says its tenor is more personal than his other writings. POL4 writes about this colleague's work and ideas and ends his article by stating: 'I should love to have heard his arguments and to have been defeated by his wit and intelligence. I am deeply sorry this will never happen'. And POL4's conclusion reminds POL5 of how she once ended an article speaking from the heart when writing about a political crisis that she felt had potential ramifications for the United Kingdom as well as for the country where it originated. Hence, although British politicians 'were concerned not to alarm the public', POL5 recounts how she

(27) POL5: ... ended up with something saying [like] 'I for one want the risks revealed, and I want to make these judgements'. And ... there is sometimes scope for injecting a personal note as well, saying, I'm not just some machine writing but a human being

POL5's analysis of POL3's 'It is in the spirit of considerable uncertaintyand, I hope, humility - that the forecasts presented above are reported' 
also judges the writer to have 'injected a personal note' to 'display his humanness and his lack of dogmatism'.

\section{Discussion}

Exploring the textual effects personal pronouns help academic writers create via interviewing allows us an insight into the writers' motivations, which a corpus-based discourse analytical approach does not. We saw in Extract (3), for instance, that POL5 felt able to include the reader in the argument via an inclusive pronoun because she was sufficiently confident that the audience would accept her arguments. While a corpus-based analyst may well have come to the conclusion that this was indeed the reason an inclusive pronoun was introduced, this would have been speculation on the analyst's part. Interviews to some extent allow us to shift the burden of interpretation from the researcher onto the writer. Although of course the writer's recollection of intentions may be as inaccurate as the researcher's interpretation-consider the time that will have elapsed between the writing of the text and the researcher interviewing the writer about the motivations that lie behind the writing - it is nevertheless reasonable to argue that a deeper understanding and appreciation of writer motivations should result. Similarly, it is also reasonable to assume that asking informants to comment on colleagues' writing in the same field may provide us with insights that could escape the discourse analyst, because the interviewees possess a disciplinary knowledge that the analyst does not.

What is noticeable from the interview data is the writers' preoccupation with ensuring their work is maximally persuasive. While social constructionism sometimes gets a bad press for overstating the writer's emphasis on persuasion rather than 'facts', it is intriguing to note that the informants echo the language of social constructionists like Gilbert and Mulkay (1984), Knorr-Cetina (1981), and Latour and Woolgar (1979) when they talk about using 'we' to 'get a conspiracy going with the reader' (POL4), or to make the text 'a little less daunting' and 'more attractive' for the reader (POL2). Writers are also aware that they must hedge those claims they advance which are necessarily speculative in order to enhance the chances of audience ratification. Hence, POL3's use of ' $I$ ' to underscore the fact that the election forecasts he expounds are 'a personal view' only, leaving the readership free to disagree, and POL4's use of 'I think' to convey that his arguments are merely 'conjecture'. Indeed, even those pronouns that help writers signal their forthcoming arguments can be seen as acting rhetorically; by warning the readers that the results will 
be delayed, writers seek to guard against what POL5 describes as 'impatience' on the part of the readership for the writer to cut to the chase. In acknowledging the audience's concerns, the writer hopes to maintain goodwill and ensure their arguments are given fair consideration. Similarly, as well as indicating what is to follow, signaling devices such as 'Moreover, as I argue later' are said by POL4 to help writers underscore their conviction that a said argument is valid. The fact that these excerpts appear to act as rhetorical and organizational devices simultaneously is in line with a recent re-evaluation of the role of metadiscourse by Hyland and Tse (2004), who assert that what has traditionally been thought of as textual metadiscourse-language said to merely serve to organize the propositional content of a text (see Mauranen 1993; Vande Kopple 1985) - can also be seen to act interpersonally, helping to make the audience 'aware of the writer's preferred interpretations' (2004: 164). The fact that pronouns help informants flag up the newsworthiness of their contribution can also be seen as a persuasive tactic, encouraging the audience to see the writer's paper as advancing the frontier of disciplinary knowledge. At the same time, however, both POL3 and POL5 ('I was just in "we" mode really") make clear that this rhetorical element in academic prose is sometimes introduced unconsciously by the writer, reminding us that we should beware of reading intentionality into every instance of apparent rhetoricity.

It is reassuring that the seven textual effects discussed here which the informants identify that 'I' and 'we' help to construct are fairly similar to those functions identified by other corpus-based studies. The signaling function, for instance, is akin to Harwood's (2003) 'Discourse Guide', Hyland's (2002) 'Stating a Purpose', and Tang and John's (1999) 'Guide' categories. The category where pronouns help writers elaborate the logic or method of an argument or procedure echoes Harwood's (2003) 'Procedural "I"/"we", Hyland's (2002) 'Explaining a Procedure', and Tang and John's (1999) 'Recounter of the Research Process'. The contribution/ newsworthiness category is similar to Harwood's (2003) and Hyland's (2002) 'Stating Results/Claims', and Tang and John's (1999) “I" as Originator'. And while these taxonomies do not feature categories like helping or including the readership, or hedging claims, Harwood (2003) and Hyland (2001b, 2002) discuss at length how pronouns help to bring about these effects at the same time as they are performing one of the other pragmatic functions in the researchers' taxonomies. Indeed, Hyland (2001a: 559) convincingly demonstrates how inclusive pronouns help construct positive politeness, 'binding writer and reader together'. Hyland (2001a: 560) also speaks of how inclusive 'we' can act as both a discourse guide and a rhetorical device to enhance the persuasiveness of the text, 
arguing that 'we can be employed to guide readers through an argument and towards a preferred interpretation of a phenomenon'. Similarly, Hyland (e.g., 1996, 1997, 1998a, 1998b), along with Markkanen and Schröder (1992) and Myers (1989), has also written of how pronouns can function as hedges to reduce face-threatening acts (FTAs).

Hence, the study supports Hyland's assertion that pronouns can be polypragmatic, serving to create two or more textual effects. It therefore reveals the difficulties of attempting to categorize each and every pronoun as helping the writer perform a single function. Thus I have noted in the analysis that, for instance, some of the extracts identified as serving to make the readership feel included can also be seen as helping to make the text reader-friendly. Indeed, there were times when the informants were explicit that two effects were being created simultaneously, as in the following extract from POL2, who claims the pronouns help to both underscore his research contribution and enhance the readability of the text:

(28) POL2: and ... where we do the model, I think it's a combination of both things. I mean on the one side trying to make the text more easily accessible, make it more human, but also here slightly to emphasize where we deviate from other models that are out there, which is always quite important. So you use the we form ... to make sure that people recognize it, to pick up 'ok, this is slightly different'.

\section{Conclusions}

While I have been preoccupied with comparing and contrasting the corpus-based and interview-based approaches in this article because personal pronouns have principally been investigated via the corpus-based approach, and because my own study takes an interview-based approach, it would be misleading to give the reader the impression that researchers have only these two approaches to choose from if they wish to study academic discourse in general and pronouns in particular. Indeed, future investigations that focus on pronouns could make use of a number of alternative approaches, and Polio's (2003) subdivision of studies of writing into those that focus on texts, processes, participants, and context is helpful in making these alternatives apparent. ${ }^{14}$ While corpus-based approaches obviously concentrate on the text, pronoun studies researching process could focus on writers' pronoun choices and revisions while composing, using methods such as think-aloud, talk-aloud, and stimulated recall, as well as interviews (see, for instance, Bosher 1998; Emig 1971; 
Zamel 1983). Studies of pronouns focusing on the participants consider writers' attitudes and beliefs toward writing, and of course their sociocultural backgrounds, which shape and help to explain these views. Again, multiple methods can and should be used in these investigations: in Curry and Lillis's (Curry and Lillis 2004; Lillis and Curry 2006) studies of multilingual scholars working outside English-speaking countries who publish in English, analysis of the writers' texts and interviews with the writers are combined with observations of the scholars' local environments and analysis of journal reviewers' and editors' comments on the informants' drafts, as well as analysis of the comments the writers receive from text correctors, disciplinary colleagues, and nonprofessionals. ${ }^{15}$ Similar studies of students' pronoun use following Curry and Lillis's methodology could also be carried out. Polio (2003) includes research that draws upon the insights of contrastive rhetoric as participant-focused; and crosscultural studies of pronoun use by non-native academics like Duszak (1994), Mauranen (1993), and Vassileva (1998) are obviously relevant here. While research of this type could be corpus based, clearly the approach would vary markedly from what I have done here: corpora of the writer's work in English as well as in the writer's L1 would ideally be required, again perhaps supplemented with interviews (see Connor 1996 for other suggestions). Finally, what Polio (2003) calls the focus of social context includes genre analysis studies (e.g., Swales 1990; Johns 2002), which describe what target texts look like - and, in relation to pronouns, when and how these are used. In this case, a corpus-based approach would seem appropriate.

Returning once again to corpora and interviews specifically, it is important to acknowledge that responses obtained via interview can be less than valid and/or reliable. As Patton (2002: 306) points out, these potential distortions can occur 'due to personal bias, anger, anxiety, politics, and simple lack of awareness since interviews can be greatly affected by the emotional state of the interviewee at the time of the interview'. In addition, Patton (2002) speaks of the well-known problem of recall error, the potential effects of the relationship between the interviewer and the interviewee, and the possibility of self-serving interviewee responses (see also Holstein and Gubrium 2003 for a detailed discussion of how interview data are potentially problematic). All in all, then, qualitative interviews can never result in an unproblematic 'excavation of facts' (Mason 2002: 64; see also Kvale 1996: 3-4). However, it should be recognized that corpus-based approaches also have their shortcomings. Chief among these is that corpora can provide only a limited insight in themselves as to the writer's intended effects of his/her text. The corpus discourse analyst is unlikely to possess a specialist's knowledge of all the fields he/she is 
studying and will therefore be obliged to make a best guess about the writers' motivations. I therefore close by suggesting that interviews can usefully complement corpus-based analysis of academic writing, and will be particularly useful for EAP teacher-researchers and students. While corpus analysis can throw up disciplinary and generic similarities and differences, interviews allow us to get a deeper sense of why texts look the way they do. And while I recognize that some readers may feel, along with one of the reviewers, that the interviewees' interpretations of their own or their colleagues' pronouns is as contestable and no more reliable than the interpretations of the corpus discourse analyst, and while I also acknowledge that it is hardly guaranteed that readers will interpret the pronouns in the same way as the texts' authors (cf. Fish 1980; Iser 1974, 1978; and others on reader-response theory), I reiterate the case for listening to what the authors say: they provide a glimpse of a discipline-specific knowledge that the discourse analyst (who is not likely to be a member of the discipline-specific community in question) cannot access alone. Indeed, in a companion study (Harwood 2006) I show how interviews with the same informants on appropriate and inappropriate pronoun usage shed light on the nature of the discipline of political science itself. Informants report that they are members of a broad disciplinary church that embraces everything from 'number-crunchers' and 'full-blown positivists' at one end of the spectrum and discourse analysts and ethnographers at the other. They further report that these various subdisciplinary communities have different tastes when it comes to (non-)pronoun use. While those researchers 'who think they're scientists' may have a preference for pronoun-free text, political philosophers are likely to try to use pronouns to inject their own voice into the (highly discursive) text. In short, then, EAP teacher-researchers and students can investigate specific textual and/or generic features via corpus analysis, and then interview academic writers - students as well as lecturers-about their writing practices and about their own use of these features in their writing.

\section{Notes}

* I would like to thank Jo McDonough and three anonymous reviewers for their constructive and insightful comments on earlier versions of this article.

1. A reviewer pointed out that this brief account of research on pronouns is far from exhaustive, and does not cover a number of alternative approaches to pronoun analysis. While the review is focused for reasons of space and relevance on the pragmatic functions of pronouns in academic discourse, I refer interested readers to a number of other works, specifically (i) discourse analytic studies of pronouns, in particular to De Fina's 
(1995) analysis of pronouns in political discourse, and to the same author's (2003) work on how pronouns are used in immigrant narratives as part of the subjects' identity construction; and (ii) studies of cross-cultural variation in academic discourse/pronoun usage (Duszak 1994; Mauranen 1993; Vassileva 1998). Both sets of literature involve taking a sociocultural perspective toward pronoun use, a perspective I say more about later on.

2. The role played by the cotext can be seen from the discussion around data extracts (9) and (11), for instance; while clearly the cotext in extracts like 'In this article, I explore' discussed in section 5.5 also contributes toward signaling the writer's intentions and arguments.

3. Hence at times the interview data reproduced includes stretches of interviewer dialogue as well as that of the interviewees. Researchers speak of how qualitative interviews are 'joint accomplishments' (Dingwall 1997: 56) between interviewer and interviewee, and are therefore co-constructed (cited in Rapley 2001: 304; see also Holstein and Gubrium 2003).

4. This process whereby the reader infers meaning is discussed in connection to readerresponse theory later on.

5. Hesitations and repetitions have been removed from the transcripts. Dots (...) indicate part of the transcript has been omitted, and square brackets [ ] indicate additional information has been added by the author.

6. As a reviewer pointed out, however, the writers' choices regarding pronoun usage are also partly determined by whether their articles are single-authored or coauthored.

7. A reviewer pointed out that the 'readership' can in fact be a less than homogeneous entity, in terms of disciplinary knowledge, background, expertise, etc. Hence while writers may sometimes assume the readership is possessed of a certain level of disciplinary knowledge, as in Extract (4), this is not always the case; sometimes their writing is shaped - and their pronouns deployed - with less knowledgeable readers in mind, as POL2 makes clear in Extract (6).

8. Here and elsewhere in the interview data, informants' accounts feature hedges that can be seen to weaken the conviction of their arguments. As a reviewer pointed out, attempting to directly read off informants' intentions and motivations from the data while ignoring hedges limits the analysis. A conversational analytic approach, for instance, would have probed the data at a deeper level. Some of the limitations of interview-based approaches in general are discussed in the conclusion.

9. I follow Hyland's (1998c: 443) definition here: hedges 'mark the writer's reluctance to present or evaluate propositional information categorically'. Hyland's definition is broad and makes sense in the context of the present discussion, which identifies a range of textual effects that can result from deploying a hedge.

10. In fact, the extract in question from POL5's text, which she discusses in Extracts (1)(3), uses inclusive 'we' ('we can see clearly ... in Table 3 ...') rather than 'you'. 'You can see' would of course be far more face-threatening to the readership than 'we can see'. However, POL5's 'we can see' is still more face-threatening than POL4's 'I find it helpful ...', where the readers are given the option of not finding POL4's table helpful.

11. Here is an instance of how informants sometimes reported that they would use a pronoun to perform the same pragmatic effect as the pronouns in their colleagues' texts. See Extracts (17), (22), and (26) for more examples of this. However, there were occasions when informants made it clear that they would not use a pronoun to perform a particular function in the same way as their colleagues. This is discussed in detail in my companion study (Harwood 2006). 
12. The pronouns in POL2's text also of course help to describe the research procedure. This is an instance of how 'I' and 'we' can construct two or more effects simultaneously. I comment on this in the discussion section.

13. POL2 uses exclusive 'we' here and 'us' in Extract (24) when discussing how pronouns emphasize 'what we have done' because his text is coauthored (although he reports that while the actual research was done collaboratively, he wrote the paper up himself).

14. Although as Polio (2003) acknowledges, her categories can in fact overlap in practice.

15. A discourse analytic study that focuses on pronouns and takes these sociocultural factors into account is De Fina (2003).

\section{References}

Banks, D. (1994). Hedges and how to trim them. In 9th European Symposium of LSP: Applications and Implications of Current LSP Research, M. Brekke, O. Andersen, T. Dahl, and J. Myking (eds.), 589-592. Bergen: University of Bergen.

Berkenkotter, C. and Huckin, T. N. (1995). Genre Knowledge in Disciplinary Communication: Cognition/Culture/Power. Hillsdale, NJ: Lawrence Erlbaum.

Bernhardt, S. A. (1985). The writer, the reader, and the scientific text. Journal of Technical Writing \& Communication 15 (2): 163-174.

Bosher, S. (1998). The composing process of three Southeast Asian writers at the postsecondary level: An exploratory study. Journal of Second Language Writing 7: 205-242.

Chang, Y.-Y. and Swales, J. M. (1999). Informal elements in English academic writing: Threats or opportunities for advanced non-native speakers? In Writing: Texts, Processes and Practices, C. N. Candlin and K. Hyland (eds.), 145-167. Harlow: Longman.

Cohen, L., Manion, L., and Morrison, K. (2000). Research Methods in Education, 5th ed. London: RoutledgeFalmer.

Connor, U. (1996). Contrastive Rhetoric. Cambridge: Cambridge University Press.

Curry, M. J. and Lillis, T. (2004). Multilingual scholars and the imperative to publish in English: Negotiating interests, demands, and rewards. TESOL Quarterly 38 (4): 663688.

De Fina, A. (1995). Pronominal choice, identity, and solidarity in political discourse. Text 15 (3): 379-410.

-(2003). Identity in Narrative: A Study of Immigrant Discourse. Amsterdam: John Benjamins.

Dingwall, R. (1997). Accounts, interviews and observations. In Context and Method in Qualitative Research, G. Miller and R. Dingwall (eds.), 51-65. London: Sage.

Dubois, B. L. (1987). 'Something on the order of around forty to forty four': Imprecise numerical expressions in biomedical slide talks. Language in Society 16: 527-541.

Duszak, A. (1994). Academic discourse and intellectual styles. Journal of Pragmatics 21: 291-313.

Emig, J. (1971). The Composing Process of Twelfth Graders. Urbana: National Council of Teachers of English.

Fish, S. (1980). Is There a Text in This Class? Cambridge: Harvard University Press.

Gilbert, G. N. (1977). Referencing as persuasion. Social Studies of Science 7: 113-122.

Gilbert, G. N. and Mulkay, M. (1984). Opening Pandora's Box: A Sociological Analysis of Scientists' Discourse. Cambridge: Cambridge University Press.

Haggan, M. (2004). Research papers in literature, linguistics and science: Dimensions of attraction. Journal of Pragmatics 36: 293-317. 


\section{Nigel Harwood}

Harwood, N. (2003). Person markers and interpersonal metadiscourse in academic writing: A multidisciplinary corpus-based study of expert and student texts. Unpublished Ph.D. thesis, Canterbury Christ Church University College.

- (2005a). 'I hoped to counteract the memory problem, but I made no impact whatsoever': Discussing methods in computing science using I. English for Specific Purposes 24: 243267.

- (2005b). 'Nowhere has anyone attempted ... In this article I aim to do just that'. A corpus-based study of self-promotional $I$ and $w e$ in academic writing across four disciplines. Journal of Pragmatics 37: 1207-1231.

- (2005c). 'We do not seem to have a theory ... The theory I present here attempts to fill this gap': Inclusive and exclusive pronouns in academic writing. Applied Linguistics 26 (3): $343-375$.

-(2006). (In)appropriate personal pronoun use in political science: A qualitative study and a proposed heuristic for future research. Written Communication 23 (4): 424-450.

Holstein, J. A. and Gubrium, J. F. (1995). The Active Interview. Thousand Oaks, CA: Sage. - (2003). Inside interviewing: New lenses, new concerns. In Inside Interviewing: New Lenses, New Concerns, J. A. Holstein and J. F. Gubrium (eds.), 3-30. Thousand Oaks, CA: Sage.

Hyland, K. (1996). Writing without conviction? Hedging in science research articles. Applied Linguistics 17 (4): 433-454.

-(1997). Scientific claims and community values: Articulating an academic culture. Language \& Communication 17 (1): 19-31.

-(1998a). Boosting, hedging and the negotiation of academic knowledge. Text 18 (3): 349382.

- (1998b). Hedging in Scientific Research Articles. Amsterdam: John Benjamins.

- (1998c). Persuasion and context: The pragmatics of academic metadiscourse. Journal of Pragmatics 30: 437-455.

- (2001a). Bringing in the reader: Addressee features in academic articles.' Written Communication 18 (4): 549-574.

- (2001b). Humble servants of the discipline? Self-mention in research articles. English for Specific Purposes 20: 207-226.

- (2002). Authority and invisibility: Authorial identity in academic writing. Journal of Pragmatics 34: 1091-1112.

Hyland, K. and Tse, P. (2004). Metadiscourse in academic writing: A reappraisal. Applied Linguistics 25 (2): 156-177.

Iser, W. (1974). The Implied Reader. Baltimore: John Hopkins University Press.

- (1978). The Act of Reading. Baltimore: John Hopkins University Press.

Ivanič, R. (1998). Writing and Identity: The Discoursal Construction of Identity in Academic Writing. Amsterdam: John Benjamins.

Janney, R. W. (2002). Cotext as context: Vague answers in court. Language \& Communication 22: 457-475.

Johns, A. M. (2002). Genre in the Classroom: Multiple Perspectives. Mahwah, NJ: Lawrence Erlbaum.

Kaufer, D. and Geisler, C. (1989). Novelty in academic writing. Written Communication 6: 286-311.

Knorr-Cetina, K. D. (1981). The Manufacture of Knowledge. An Essay on the Constructivist and Contextual Nature of Science. Oxford: Pergamon Press.

Kuo, C.-H. (1999). The use of personal pronouns: Role relationships in scientific journal articles. English for Specific Purposes 18 (2): 121-138.

Kvale, S. (1996). InterViews: An Introduction to Qualitative Research Interviewing. Thousand Oaks, CA: Sage. 
Latour, B. (1987). Science in Action: How to Follow Scientists and Engineers through Society. Milton Keynes: Open University Press.

Latour, B. and Woolgar, S. (1979). Laboratory Life: The Social Construction of Scientific Facts. Beverly Hills: Sage.

Law, J. and Williams, R. J. (1982). Putting facts together: A study of scientific persuasion. Social Studies of Science 12: 535-558.

Lillis, T. and Curry, M. J. (2006). Professional academic writing by multilingual scholars: Interactions with literacy brokers in the production of English-medium texts. Written Communication 23 (1): 3-35.

Markkanen, R. and Schröder, H. (1992). Hedging and its linguistic realizations in German, English and Finnish philosophical texts: A case study. In Fachsprachliche Miniaturen: Festschrift für Christer Laurén, M. Nordman (ed.), 121-130. Frankfurt: Peter Lang.

Mason, J. (2002). Qualitative Researching, 2nd ed. London: Sage.

Mauranen, A. (1993). Cultural Differences in Academic Rhetoric: A Textlinguistic Study. Frankfurt: Peter Lang.

Miles, M. B. and Huberman, A. M. (1994). Qualitative Data Analysis: An Expanded Sourcebook, 2nd ed. Thousand Oaks, CA: Sage.

Myers, G. (1989). The pragmatics of politeness in scientific articles. Applied Linguistics 10 (1): $1-35$.

Patton, M. Q. (2002). Qualitative Research and Evaluation Methods, 3rd ed. Thousand Oaks, CA: Sage.

Pennycook, A. (1994). The politics of pronouns. ELT Journal 48 (2): 173-178.

Polio, C. (2003). Research on second language writing: An overview of what we investigate and how. In Exploring the Dynamics of Second Language Writing, B. Kroll (ed.), 35-65. Cambridge: Cambridge University Press.

Prince, E. F., Frader, J., and Bosk, C. (1982). On hedging in physician-physician discourse. In Linguistics and the Professions: Proceedings of the Second Annual Delaware Symposium on Language Studies, R. J. Di Pietro (ed.), 83-97. Norwood: Ablex.

Quirk, R., Greenbaum, S., Leech, G., and Svartvik, J. (1985). A Comprehensive Grammar of the English Language. Harlow: Longman.

Rapley, T. J. (2001). The art(fullness) of open-ended interviewing: Some considerations on analysing interviews. Qualitative Research 1 (3): 303-323.

Salager-Meyer, F. (1994). Hedges and textual communicative function in medical English written discourse. English for Specific Purposes 13 (2): 149-170.

- (1997). I think that perhaps you should: A study of hedges in written scientific discourse. In Functional Approaches to Written Text: Classroom Applications, T. Miller (ed.), 105118. Washington, DC: United States Information Agency.

Swales, J. M. (1990). English in Academic and Research Settings. Cambridge: Cambridge University Press.

Tang, R. and John, S. (1999). The 'I' in identity: Exploring writer identity in student academic writing through the first person pronoun. English for Specific Purposes 18: S23-S39.

Vande Kopple, W. J. (1985). Some explanatory discourse on metadiscourse. College Composition and Communication 36 (1): 82-93.

Vassileva, I. (1998). Who am I/who are we in academic writing? A contrastive analysis of authorial presence in English, German, French, Russian and Bulgarian. International Journal of Applied Linguistics 8 (2): 163-190.

Wales, K. (1980). Exophora re-examined: The uses of we in present-day English. UEA Papers in Linguistics 12: 21-44.

-(1996). Personal Pronouns in Present-Day English. Cambridge: Cambridge University Press. 


\section{Nigel Harwood}

Whitley, R. (2000). The Intellectual and Social Organization of the Sciences, 2nd ed. Oxford: Oxford University Press.

Wolcott, H. F. (2001). Writing Up Qualitative Research, 2nd ed. Thousand Oaks, CA: Sage. Zamel, V. (1983). The composing processes of advanced ESL students: Six case studies. TESOL Quarterly 17: 165-190.

Nigel Harwood is a lecturer at the University of Essex. He has published papers on how pronouns are used in student writing and on taking a corpus-based critical pragmatic approach to EAP. His main research interests are in the areas of academic writing, EAP, materials design, and corpus-driven pedagogy. Address for correspondence: Department of Language and Linguistics, University of Essex, Wivenhoe Park, Colchester CO4 3SQ, UK 〈nharwood@essex.ac.uk〉. 